\title{
研究論文
}

\section{雲南省䖯豆 枯萎病和莖腐病的研究（其一)}

\author{
俞大䌅 方中達
}

在全世界所有生產 㪇豆的國家裹面，中茫人 民共和國佔了第一位。我椚全國栽培算豆的面敌，

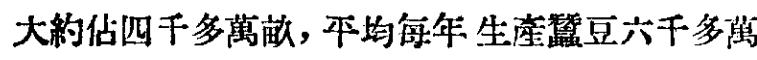
市石。筑豆是水稳區裹面一湖比較合乎理想的冬 季作物, 它的生長期比小麥短, 收權較早, 使農比 有充分的時間耕作稻田。它的習性適宜温濕的上

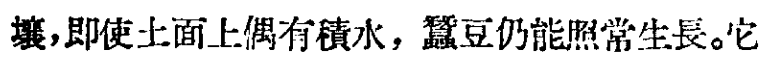

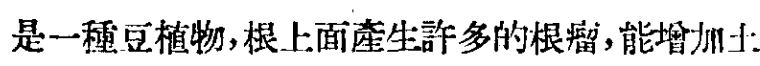
地的肥力, 它也是不林科作物一僻最適合的輪作

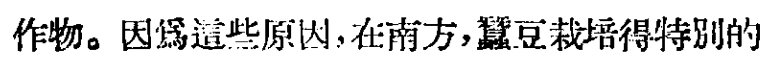

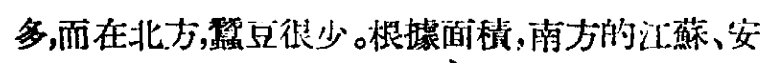
微、湖北、湖南、汇西、浙江、四川、福建、廣東、廣酒 、雲南和貴州十二省, 共堹蚠豆三:六百多萬放;

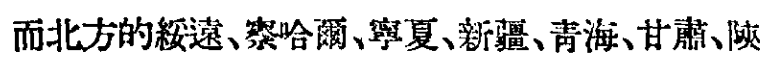
西、山西、山東、河北和河南十一省,僅只有軖豆六

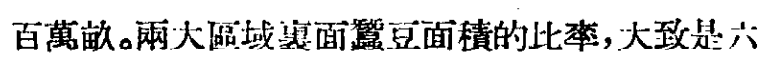
比一。根據童量，南方和北方平均每年琶豆的策量 的比率, 大約是十一比一。

筑豆是南方一個重慗的冬季作物, 而在雲南 省, 更特品的重要。㯰是如何說 法呢? 讓我們將全

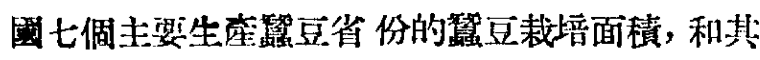
他约倜主要冬季作物的面皘作比較, 就可以看H 鄞豆在雲南省是何等的重要。(表一)

分析 '表一' 襄面所列的数字, 根據面绩, 四川 居首位, 順次是雲南、湖北、江蘇、浙江、湖南和江 西。僅只根㨜面皘的大小，並不能筼示荣一璉作物

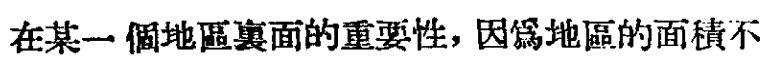
同, 例如, 四川和浙江兩省的裁培總面積, 就相沾 很遠, 因此必須要根據某一個區域裹面各個主要
作物裁培面棈的百分比率, 方線 可以知道一個作

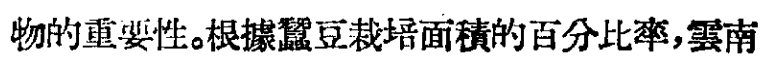
居第一位，順次是湖南、浙江、四川、湖北、江西和

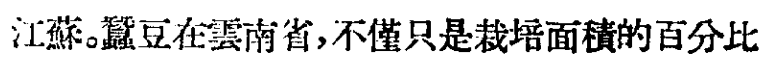
率最大, 而且和其他主管冬季作物的载培面積百

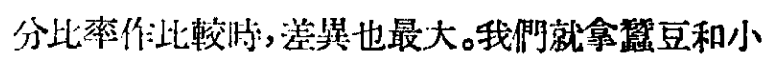

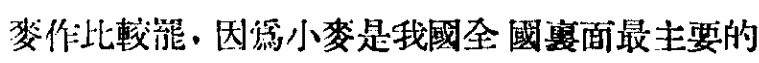
冬季作物, 算豆和小麥裁培面積百分率的比率: 四 川是一比二,湖北一比三, 江蕉一比叫, 浙江三比

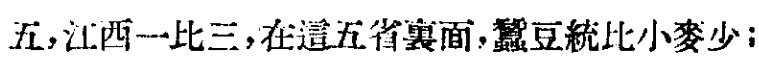
湖南一一一比一, 网種作物面锖相登哭幾; 雲南

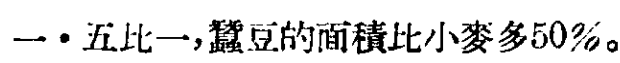

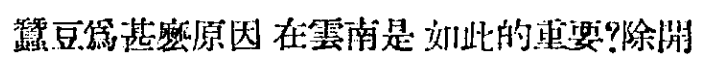

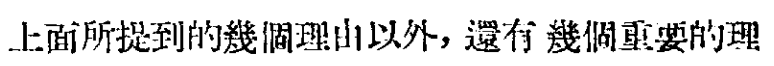
由:雲南各縣, 大牛是四面環山, 當打有一塊低地,

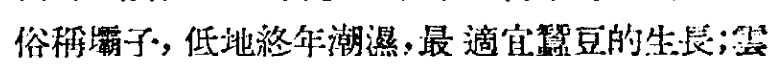

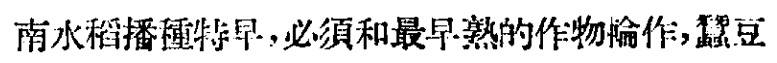
的成熟期本來已比小麥早, 而在雲南虽秋季水稻

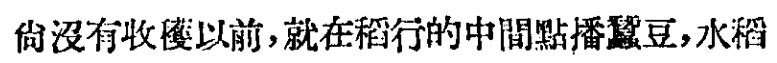
收割的時候, 螯豆已長達幾寸高, 因此更可以提前

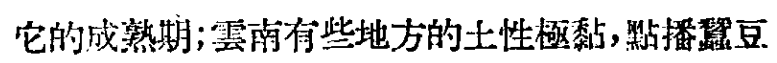
比撒播小麥比較省工; 又雲南多山, 主要的交通工

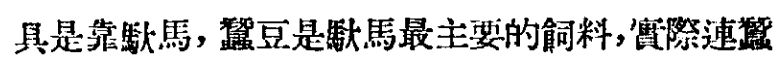

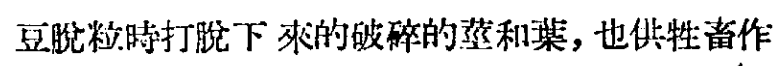

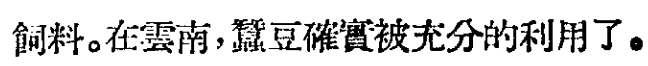

我們在雲南前媵住了八年。曾楥到南部、東部 和西部去調查作物的病害, 立即發現琵豆感染有 一程極劇烈的病害。在比較高的田或是 地寒面是 十分嚴重的, 時常有整塊的田地, 或是一大片的地 


\section{表一 中國主要生库语豆省別五種主要冬季作物栽培面皘和百分比率}

\begin{tabular}{|c|c|c|c|c|c|c|c|c|c|c|c|c|c|}
\hline \multirow{2}{*}{ 省 } & \multirow{2}{*}{ 別 } & in & 豆 & 小 & 麥 & 大 & 麥 & 跑 & 豆 & 油 & 菊 & \multicolumn{2}{|l|}{ 總 } \\
\hline & & 面謮 & $\%$ & 面 積 & $\%$ & 面 積 & $\%$ & 面稳 & $-\%$ & 面 皘 & $\%$ & 面 積 & $\%$ \\
\hline 四 & 川 & 7,891 & 14.41 & 15,158 & 27.69 & $12,0.18$ & 22.00 & 8,531 & 15.59 & 11,121 & 29.31 & 54,754 & 10 \\
\hline 雲 & & 5,649 & 39.52 & 3,485 & 24.41 & 1,946 & 13.62 & $1,8.47$ & 14.93 & 1,360 & $9.5^{2}$ & 14,291 & 10 \\
\hline 湖 & 北 & 5,071 & 11.73 & 15,127 & 34.99 & 13,908 & 32.17 & 5,225 & 12.09 & 3,899 & 9.02 & 43,230 & 10 \\
\hline iI & 铉 & 4,781 & 7.68 & 33,128 & 53.21 & 15,498 & 24.89 & 5,075 & 8.15 & 3,782 & 6.07 & 62,264 & 10 \\
\hline 浙 & 江 & 4,332 & 18.37 & 7,576 & 32.13 & 4,468 & 18.95 & 2,091 & 8.87 & 5,110 & 21.18 & ה37,5י & 10 \\
\hline 湖 & 南 & 3,581 & 21.22 & 3,330 & 19.76 & 1,839 & 10.89 & 2,093 & 12.40 & 6,081 & 35.73 & 16,879 & 10 \\
\hline 江 & 西 & 2,088 & 10.54 & 6,005 & 30.32 & 2,990 & 15.14 & $1,90 \pi$ & 9.63 & 6,807 & 34.37 & 19,804 & 100 \\
\hline
\end{tabular}

面禎單位千市效

方上面的算豆，整個枯死，顆粒無收。但是在低濕的

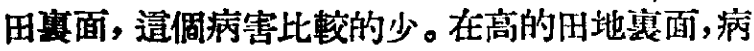

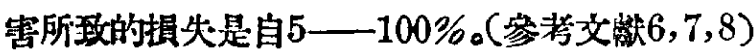

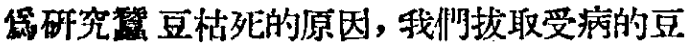
株, 割取根部, 先用清水將上面啝着的泥上洗浮, 然後浸在 $0.1 \%$ 的昇求溶液重面二十分蹱,再用消 毒清水洗去上面遗留的开采，等它們稍乾後，用消 過毒的刀,剖閶根部,向中心挑取少許變色的組織，

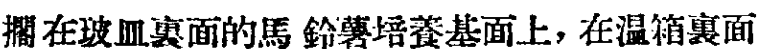
塔䓹,一俟有菌線長出後，挑取菌秝,接種在玻管

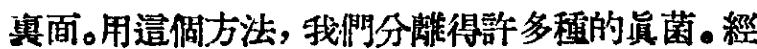

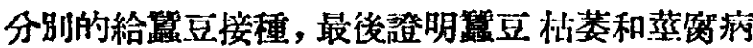
主要的病原是三種鏡》菌。因第它們和已知的鉡

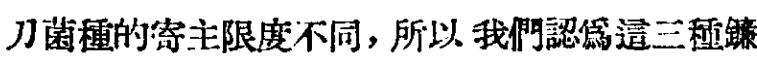
刀菌種是三個新的變種。(參考文跌 4 )

現在特造三個菌種的形態和在琶豆上面所發 生的病徽,記载在下面：

\section{(一)题豆枯菱病}

病原菌是 Fusarium avenaceum var. fabae (新變理),小型分生胞子,,不産生, 或是偶既産生,

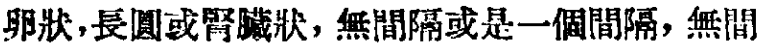
隔的胞子 $10.7 \times 3.7(8.7-13.9 \times 3.5-4.4)$ 公勿 （每公勿等於千分之一的公框），一個間隔的胞子 $13.9 \times 3.4(10.4-15.7 \times 3.3-3.4)$ 公勿。大型

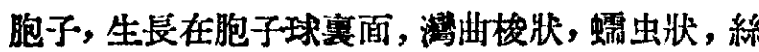
狀, 很長而窄，中部稍宽，基端紐胞長而狹，頂 端窄狹稍尖，渄曲很大，胞了最多的是五倜間隔， $55.4 \times 3.8(46.4-63.0 \times 3.5-4.2)$ 公圽, 很少 七倜間隔,十二個開隔的胞丁是例外，三倜間隔胞 $-5.42 .8 \times 3.6(34.8-47.9 \times 3.5-3.8)$ 公勿, 仙

個間䧣胞于 $49.4 \times 3.7(41.6-56.7 \times 3.5-4.4)$ 公勿, 共個閏隔胞于 $62.9 \times 3.8(56.6-73.1 \times$ 3.5 -4.5)公勿, 七個開融胞于 $73.1 \times 3.7$ 公勿, 生

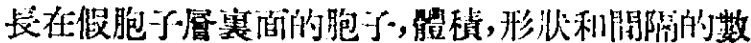

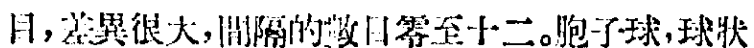

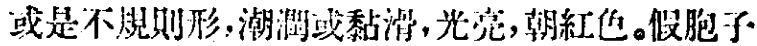

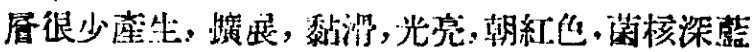

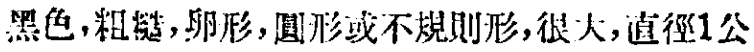

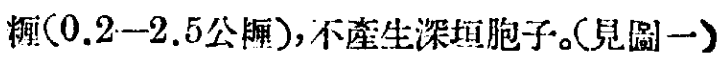

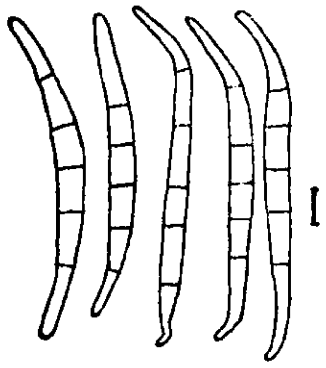

104.
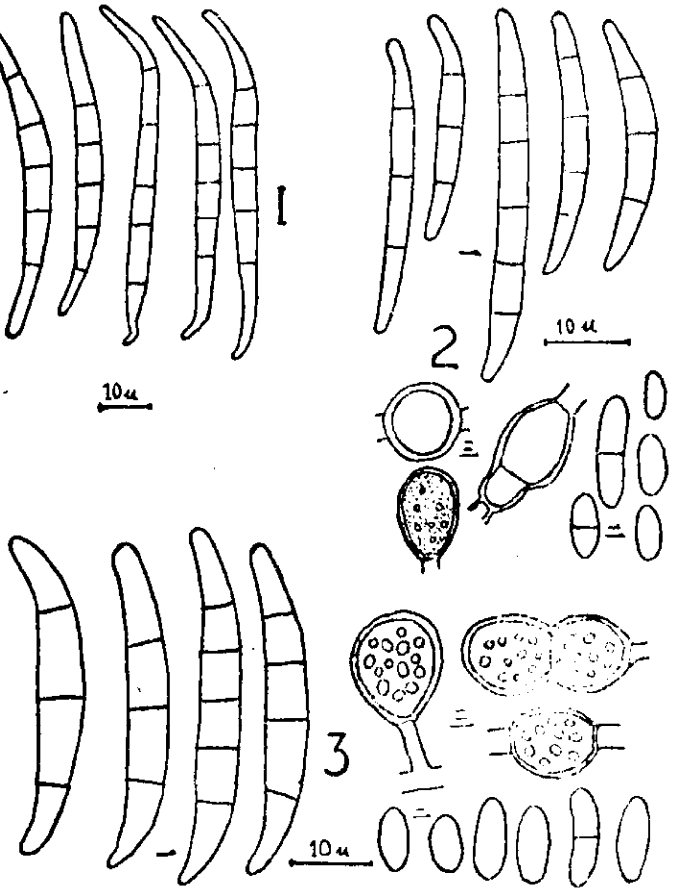

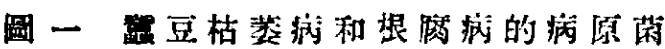
1. Fusarium avenaceum $f$. fabae 大型分生胞于.

2. F. oxysporiun f.fabae $(\rightarrow$ 大型分生脂子 (二) 小型分生胞子 (三) 暻垣胞子

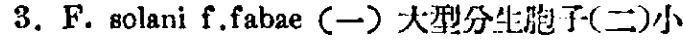
型分生胞子 (三) 厚埴胞子 


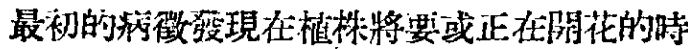

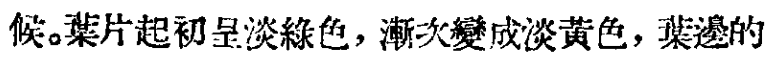

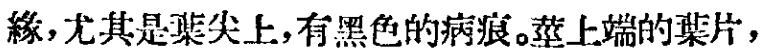
通立, 证且比正常的㱔片較堅硬。有的時候, 整株 整至變黃.自下向上，一直到頂端的棐、芽順次的 枯萎。棐片有時候變成带綵色後，很快的乾死。這

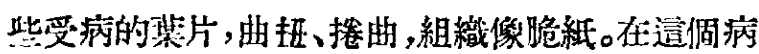

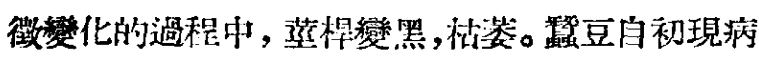
微,一星期後, 可能仙死。在田裏面, 通常需要二十 到三十天, 方螋完全恬死。病株时常比健株矮小。 (參溚文殿 6 )

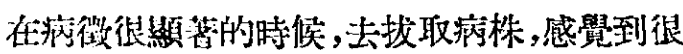
不费力，就可以將他們自上亶面拔出來。造是因缭

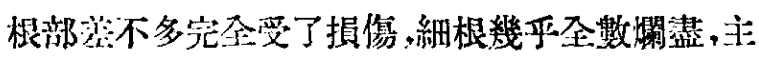

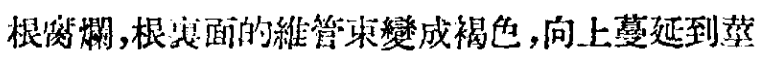
就酮。

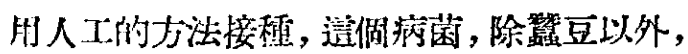

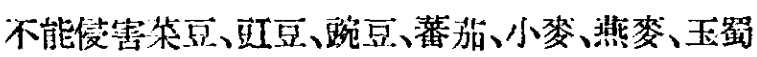
咏和胡蘿蓄。

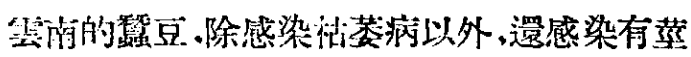

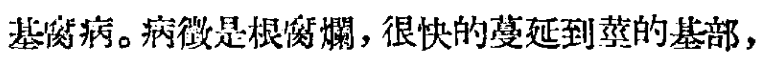
植株任一偑很短的時閒內, 完全佔死, 春不到普通

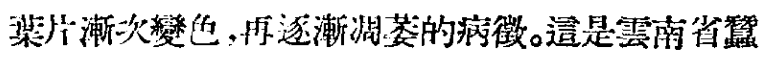

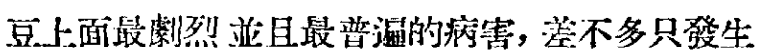

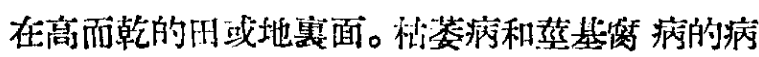
原菌是一程，學名是Fusarium avenaceum。因管致

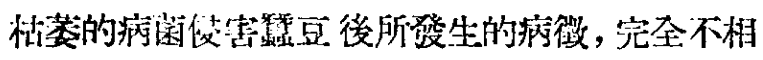

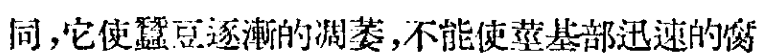

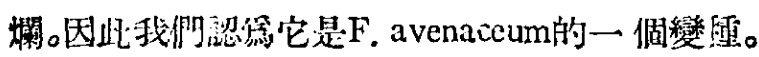

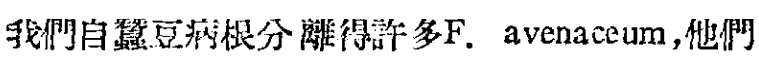
的政瘳情况很不楜同。由此可見, F. a vcnaceum包

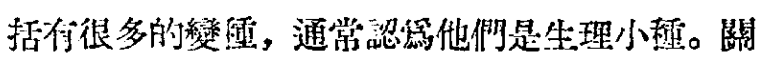
於近些菌程的形態、生理和致瘳力比較的結果, 以 後肪翟表洋綝的報告。

\section{(二)雄豆根乾腐病}

病原菌是Fusarium solani f fabae (新變轾)。 小型分生胞子生長在 分枝不規則的胞子梗上面， 卵形, 長卵形或是短桿形, $6.6 \times 2.1$ 公勿, 很少有 間隔。大型分生胞子，生長在菌絲或是稨胞子球上 面，又生長在胞子球或是胞子据上面,梭形或稍微 愐端圆形文稍微收樎, 胞子、下端稍微有柄或
是根体沼有柄，零至六倜間隔，最多的是三倜間 隔, $34.8 \times 5.2$ 公勿。丵集的分生胞子金黃色, 黄紌: 色，淡紅或乳酪色。菌核很小，深藍色或藍紫色。厚 垣胞子生長在菌綵的頂端或是中間, 大多數的是 單細胞，球形或是長圆形, $10.6 \times 10.0$ 公勿, 网個 細胞的厚垣胞子 $24.2 \times 15.1$ 公勿，厚垣胞子有的 時候五相連接成短練狀, 表面光滑或有蠋折。(圖) -, 3)

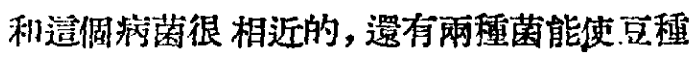
作物發生根得病:一個是Fusarium solani v. Martii f2. 致施豆的根筞病; 另一個是Fusarium solani

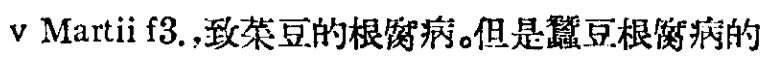
瘁原菌和他們是不相同的，因媱胞子的大小不同 和㟢生的寄主也不相同。(參考文踧 1)

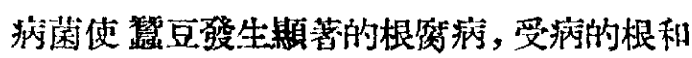

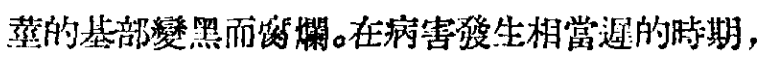
側生根和主根的一大部份萎縮亚變乾，渠片侣只 略戀黄色。在上面上植物所發生最明䫏的病微, 是 在下面的装片的邊称上面，产生大小不同的黑色

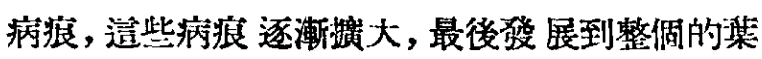
片。在蒙上端的葉片上,有形状不規則，大小不同 的黑色斑點, 生長在䕀胍的中間, 病害逐漸深沉, 葉片和蒙變黑，萎縮並怙死。藮和莖的維管束和皮

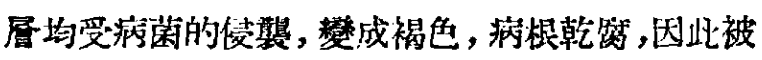

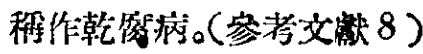

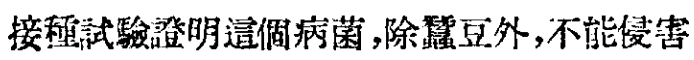

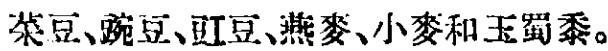

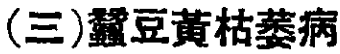

症源菌是Fusarium oxysporium v. fabae ( 新 戀鼠)。

菌絲生長茂盛。起初是灰白色,變成黃褐色和

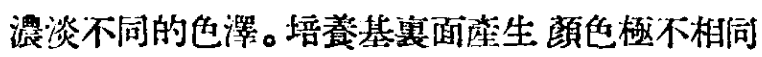
的色素。小型分生胞子很不規則的，大量的生舆在 菌棌上面，卯形、長圆形或是不規則棈圆形，大多 數的是單細胞, $7.1 \times 3.3(5.2-10.4 \times 2.1-3.5)$ 公勿。大型分生胞子很稀少，大多數的是三個 間隔，宽度均匀，或是上端略宽，近項端略微 曲, 顶端圆形, 基部很直或是画道,很少有柄,31.9 $\times 4.1$ 公勿。胞子球和胞子展稀有，菌核菌棌展深

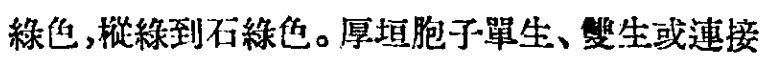
成短練,生長在囷絲的項端或是中間,球形, 庇球 
形, 外皮厚深, 褐色, 光滑, 7.3×6.9、6.6-9.1 $\times 5.8-7.4)$ 公勿。(圖一,2)

票豆在地面上各部分所墢生最䫏著的病徽, 是葉片答黄, 病柋黄色, 並多少硬化, 崺株的根和 莖的基部,並不䫏著的變他。剖開受病的根, 可以

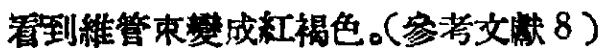

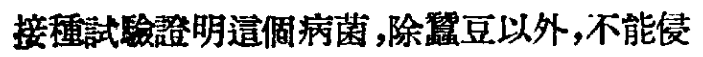

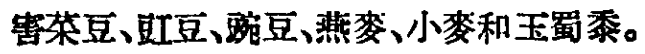

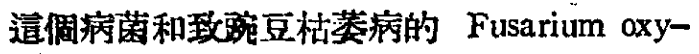
sporium f pisi 的形態和培養性質相像, 只是寄生 性不相同。我們用稳豆和䙲豆上面分離得的病菌, 交互的給琶豆和踠豆接種,所得到的結果,是踠豆

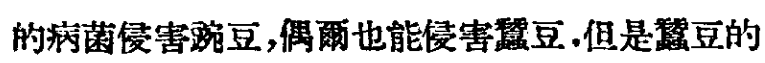

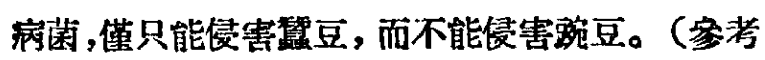
文緗 2,3 )

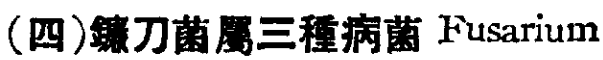
avenaceum, F Solani, v. fabae 和F。 oxysporium $v$ 。fabae在零 南省的分佈情形

因筑零南省的琶豆受邆些病菌的侵害, 蒙受 閶菆的提失，我們逐年不斷的到各綦去作探集和

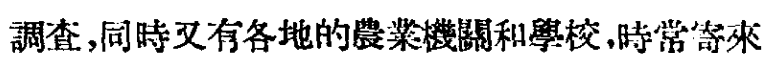

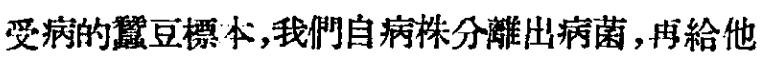

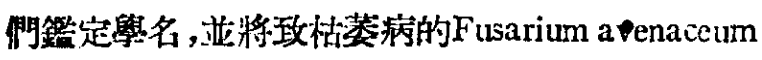

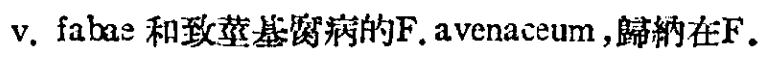
avenaceum一個學名下面。因算受時間和設储的限 制, 不能將他們分品的鑑定。根據記錄, 在雲陗役

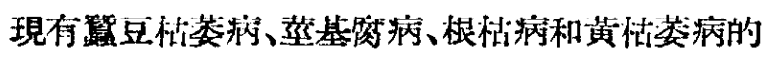

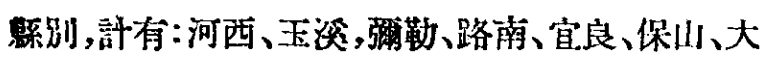
姚、永平、㢣化、祥雲、大理、楚雄、元謀、新平、陸

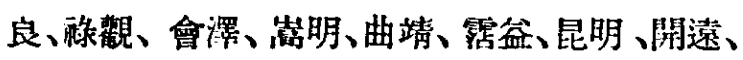

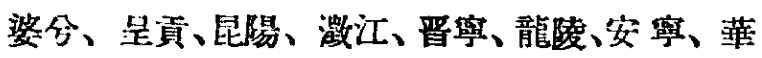
悬、和通海。㾈害分佈的情形見 “圖二”。雲南少主

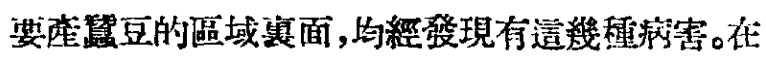
低缹或終年有水的田撉面，這些病害墢生極少，但 是在高的田或是地裹面，病害時常十分的留重。根

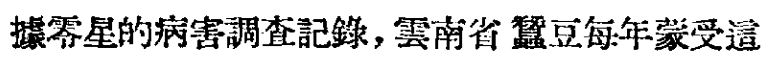
幾程病害所玟的損失估計，至少是 $1.5-2 \%$, 相賞 損失琵豆 147,000 到196,000方石。

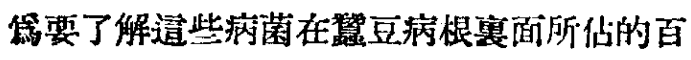

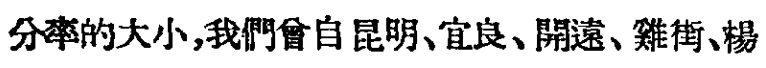

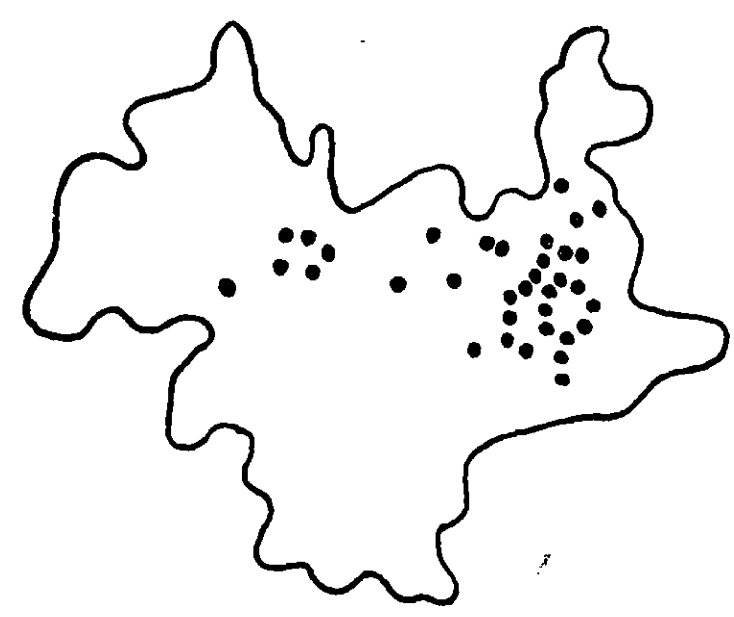

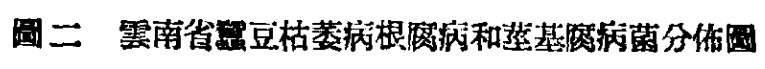

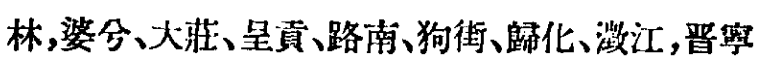
龍林、安察、華察、通海、玉添、河西和昆陽二十储

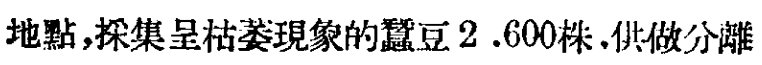
病菌的材料。現在將分離1 1337 次所得到众得的名

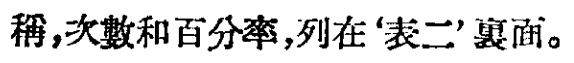

\section{表二 自賞豆病根分踓得的菌 稙名稆次数和西分率}

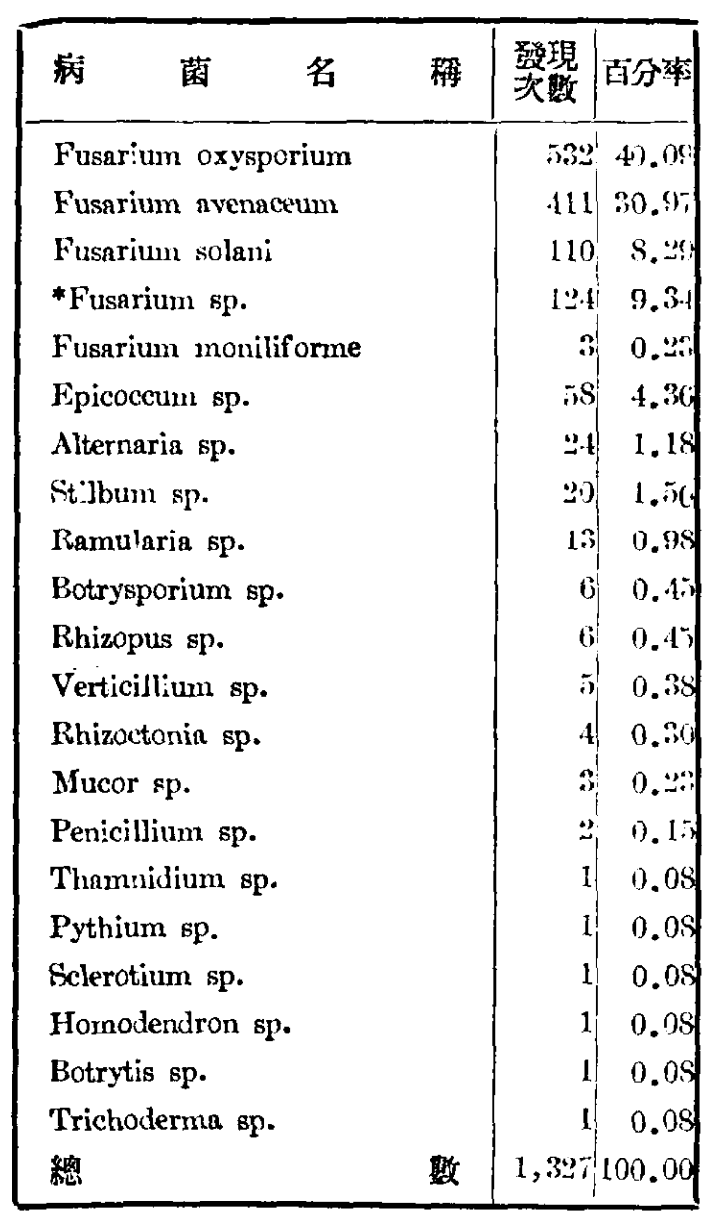

* Fusarium sp. 包括 Fusarium oxysporium, F. avearceum 和 F. solani. 
在1,327次病根分離的結果赛面, 共分離得三 整鎌刀菌鹤F Fusarium oxysporium, F. avenaceum, S. solani 1,177坎,佔全數 $88.70 \%$ 。其中以F. oxysporium最多.佔 $40.09 \%$, F. avenaceum佔 30.97 $\%$, 居次位, F.solani 最少, 僅佔 $8.29 \%$ 。此外澴 有 $9,34 \%$ 包括這三種病菌, 因䮡分灌後參雜有 别的菌, 或經初步鑑起後, 叉遺失掉了, 因此汥有将 他們作精緗的鑑定。所以在表稟面，將他們歸納在

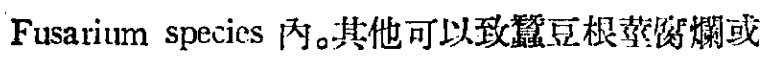

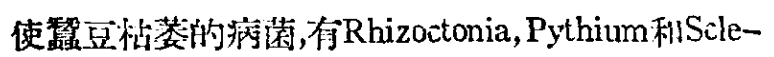
rotium 三程菌。Verticillium 在箦豆上: 是一僻寄生 力最弱的菌。它使根局部變黑死去, 莯片變黄们

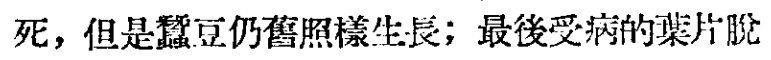
落, 新葉片照常生長, 上面不再發生疮徽, 使整個

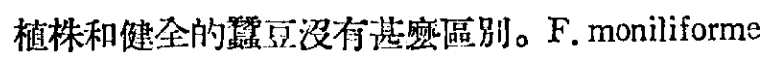
也和Vercillium一般, 在墔豆上面寄生性異常的薄 弱。這五程流菌梫現次數的總數, 僅只住 $1.07 \% 。$

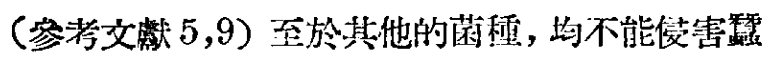

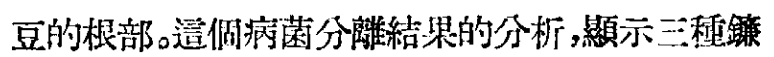
刀菌屬菌的普湴和重要性。

\section{摘 要}

蚟豆是雲南省栽 培面 積最大的一個冬季作 物。它是人民重要的食物和牲畜主數的瞲料。

雲南省的等豆感染 有幾種嚴 重的病害: 忰萎

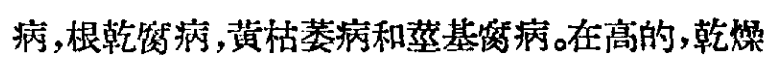
的时和地裹面, 這些病很劇烈, 尤其是蒙基病, 谌 至能特全田的䖝豆整個的毀隇。根據初步的估計，

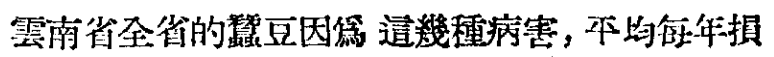
央 147,000 到196,000市石。

這些病害的病原菌均是鏻 刀屬的菌種。政枯 萎获的病原菌是Fusarium avenaceum $f$ fabae, 政 根乾华疤的病原菌是 F. solani f fabae, 玫黄枮

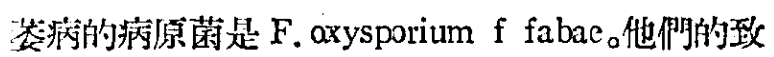

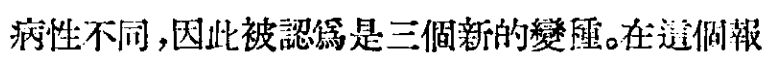

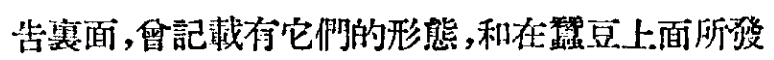

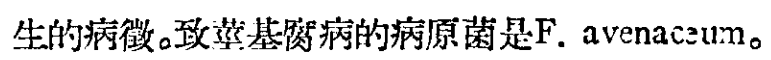

這些病菌，在雲南省分扸廣閏，並且很多。根㨜 痛根分離的結渠, Fusarium oxysporium $\mathrm{f}$ fabae最 多, F. avenaceum 次多, F. solani f fabae较少。

\section{參考文 獻}

1. Burkholder, W. H. The dry-root rot of bean. Cornell Univ. Agr. Exp. Sta. Mem. 26, 1919.

3. Jones, F. R. Stem and root-rot of peas in the United States caused by species of Fusarium. Jour. Agr. Res $20: 4: 99-475,1923$.

3. Linford, M. B. A Fusarium wilt of peas in Wisconsin. Wis. Agr. Exp. Sta. Res. Bul. 85, 1928.

4. Wollenweber, II. W., and O. A. Reinking. Die Fusarium. Ihre Beschreibung, Schadwirkung und Bekämpfung. Berlin. 1935 .

5. Yu, T. F. Relation of soil temperature to pathogenicity of Rhizoctonia solani Kuhn. on broad been seedlings. Nanking Jour. 9:369-280, 1939.

6. Fusarium diseases of broad beans. I. A wilt of broad bean caused by Fusarium avenaceum var. fabae. n. var. Phytopathology 3.1:385-393, 1944.

7. C. T. Fang. Fusarium disease of broad bean. II. Further studies on braod bean wilt caused by Fusarium arenaceum var. fabae. Phytopathology 38:331-342, 1948.

8. C. T. Fang. Fusarium disease of broad bean. III. Root-rot and wilt of braod beans caused by two new forms of Fusarium. Phytopathology 38:587-59.4, 19.18.

9. Notes on sorne weak parasitic fungi isolpte 1 from the diseased roots of broad bean. In press.

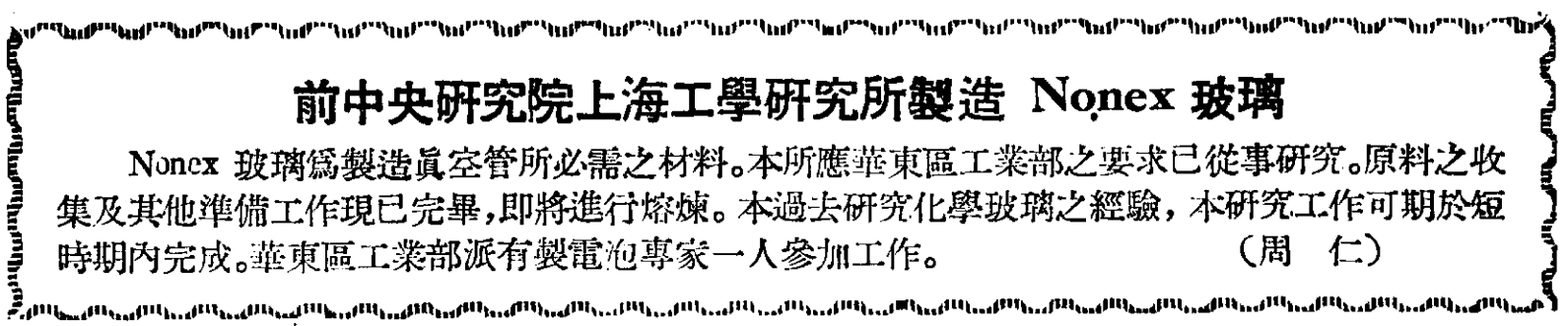

第二期 